\title{
Energy absorption capability of laminated plates made of fully thermoplastic composite
}

\author{
Simonetta Boria' (1) and Alessandro Scattina ${ }^{2}$
}

\begin{abstract}
The behaviour of composites materials, made of synthetic fibres embedded in a thermoplastic resin, subjected to low velocity impacts, was largely studied in the past. However, in the last years, the use of thermoplastic composites has been increased due to the considerable advantages in terms of recyclability of this family of materials. Thermoplastic composites are composed of polymers with different material's structure if compared to the more traditional thermoset composite. Consequently, the behaviour of these materials can be different in some loading conditions. Moreover, considering the wide range of thermoplastic composites that have been developed in the last years, the study of the behaviour of these materials, in case of impact, has not been yet widely analysed, in particular considering materials where both the matrix and the reinforcement are made of thermoplastic. In this perspective, the goal of this work is to study the behaviour of a new thermoplastic composite (PURE thermoplastic) in conditions of low velocity impact. In this material, the matrix and the fibre reinforcement are made of polypropylene both. The paper presents the results of an experimental investigation. In particular, a series of impact tests with a drop dart equipment have been carried out on laminates made of PURE thermoplastic. Laminates with different thicknesses have been taken into consideration. The influence of the impact conditions on the material's behaviour has been investigated and the capability of energy absorption has been studied. The PURE thermoplastic showed a different behaviour in terms of energy absorption and damage mechanisms if compared to the composites presented in the literature. The thickness of the laminate has had influence on the deformation and the damage mechanism of the specimens: with low thickness, the perforation of the specimen has been obtained, whereas, with the higher thickness, the specimens have shown a ductile behaviour and extended plasticity without crack tip. The contact force between the dart and the specimen has been influenced by the energy level of the impact, but with an opposite trend if compared to that of the composites studied in the literature.
\end{abstract}

\section{Keywords}

Lightweight design, laminated thermoplastic composite, low velocity impact

Date received: 5 July 2017; accepted: 26 January 2018

\section{Introduction}

Composite materials are being used in several industrial fields for their excellent strength and outstanding specific properties in terms of stiffness. ${ }^{1-3}$ In the automotive field, the recent directives proposed by the EU Commission ${ }^{4}$ aim to raise consumer awareness on fuel use and reduction of $\mathrm{CO}_{2}$ emissions of the new passenger cars. Such reduction can be achieved with different solutions: innovative propulsion systems, conversion to alternative fuel types and weight reduction. Among all, the weight reduction is the most efficient strategy for the reduction of the energy demand of vehicles and the corresponding emissions. ${ }^{5}$ Recently, the adoption of composites is strongly explored with the attempt to achieve the maximum weight reduction. The use of fibre reinforced polymers (FRPs) is perceived as a promising alternative of the metallic structures. ${ }^{6}$ Several research and development efforts were pursued to further the application of lightweight FRP composites in the automotive sector. ${ }^{7-9}$ From these works, it was shown how the frame of the vehicles made of FRP are able to guarantee a better behaviour in terms of damping and absorption characteristics of impact

'School of Science and Technology, University of Camerino, Camerino, Italy

${ }^{2}$ Department of Mechanical and Aerospace Engineering, Politecnico di Torino, Torino, Italy

\section{Corresponding author:}

Simonetta Boria, School of Science and Technology, University of Camerino, 9 Madonna delle Carceri, Camerino 62032, Italy. Email: simonetta.boria@unicam.it 
energy respect to the conventional steel structures. Moreover, the FRP structures ensure a significantly lower weight. ${ }^{8}$

However, the weight saving which can be obtained by this class of materials is still limited by overconservative design approaches. This is partially due to the poor damage tolerance of this class of material to low velocity impact (LVI) phenomena. ${ }^{10-20}$ The composite components are exposed to LVIs, during their operative life, such as runway debris on vehicle bodies. In most cases, this type of impact can induce the formation of damage, which are usually not easily detectable by a visual inspection and can cause a substantial reduction of the performance of the component. ${ }^{21-23}$ In-plane damage, such as fibre breakage and matrix cracking, and out-of-plane damage, such as delamination, are the main failure modes induced on FRP by LVIs. ${ }^{24}$ In particular, delamination is among the most dangerous failure mechanisms, because they can propagate during service, especially under compressive load, leading to a strength reduction of the whole structure. The heterogeneous nature of composite materials joined to an irregular resin distribution, fibre discontinuities and micro-gaps can cause several failure mechanisms interacting each other. Furthermore, the damage onset and evolution can be deeply influenced by the physical parameters of the impact, the environmental conditions and by the properties, the shape and the structural configuration of the impactor.

Because of all these parameters, the development of numerical tools with high reliability ${ }^{25}$ and able to exhaustively describe and predict the failure induced by the impact is a challenging task still in progress. The prediction of the impact response and of the characterization of the damage induced by the impact are topics widely treated in the literature. In the past years, analytical, numerical and experimental approaches were explored to study the effects of the LVIs on the composite structures. ${ }^{26-36}$

One of the major concern for the systematic application of composites in series production is the end-of-life treatment of FRP components. The EU ELV directives ${ }^{37}$ point out that at least the $85 \%$ of the mass of the car has to be reused or recycled. For this reason, an end-of-life treatment scenario in which the FRP components are incinerated is not more a valid possibility. Therefore, recently, there is an increasing interest in the use of polymers due to their full recyclability. However, isotropic polymers have poor strength and stiffness for their use in many engineering applications. In order to improve these properties polymers can be filled with structural reinforcements such as glass, carbon or natural fibres. Moreover, the thermoplastic composites show higher damage tolerance if compared to the traditional thermoset composite. ${ }^{38}$ Previous research showed that composites made of thermoplastic matrix (Carbon/PEEK or Glass/PEEK) presented higher properties when loaded in compression and in compression after impact with higher strains to failure respect to the thermoset composites. ${ }^{39,40}$ A recent study $^{41}$ on the comparison between thermosetting and thermoplastic composites showed that wovenply carbon fibres laminated with PEEK or PPS resin were able to reduce the extension of damages, and in particular, of the subsequent delamination, for a given impact energy, respect to laminates made of epoxy resin. This result was due to tougher matrix system in the thermoplastic composites. However, the high resin viscosity in the thermoplastics is a limitation during the production process. The impregnation of the reinforcement fibres in tightly woven or unidirectional composites could be a problem. ${ }^{42-45}$ On the other hand, the lower viscosity of the resin of a thermoset composite provides easier processing and lower content of void in the laminate. Moreover, both the material and the tooling costs for the process of the thermoplastic composites are higher than those for the thermoset ones. ${ }^{46}$ Tow-scale hybridization of synthetic fibres with polypropylene (PP) ones in thermoset matrix is able to reduce fibre damage during the impact loading due to the cushioning effect offered by the lower modulus of the PP fibres. ${ }^{47}$

The current major trends focus on simple mono component systems, made of the same material, in an effort to reduce costs and increase recyclability. In the last years, with the introduction of careful processing routes, it was possible to create a fibrous, two phase composite, in which both are polymers. The first study on single polymer composites based on oriented polyethylene (PE) fibres goes back to $1975 .{ }^{48} \mathrm{PE}$ polymer was the first candidate for most initial studies since the ultimate modulus of a linear PE molecule $(\sim 250 \mathrm{GPa})$ is much greater than the crystal lattice modulus of the helical PP molecule $(\sim 40 \mathrm{GPa}),{ }^{49-51}$ implying higher ultimate properties achievable with PE fibres. However, the lower melting temperature and the glass transition of PE mean that creep at room temperature can be problematic and maximum usage temperature is lower than that of PP, which also benefits from a slightly lower price and density. A novel method for the preparation of single-polymer composites, without the need for a separate matrix impregnation route, that is limiting by relatively low volume fractions of reinforcement, was implemented at the University of Leeds. ${ }^{52}$ Then, the limitation of a small temperature processing window was overcome by the PURE-project, conducted at the Eindhoven University of Technology, where a single polymer composite based on PP fibres embedded in the same PP matrix was studied and then patented, manufactured and delivered by Lankhorst Pure Composites bv, now DIT bv. ${ }^{53-55}$

In this perspective, this paper deals with the behaviour of such fully thermoplastic composite when subjected to impacts at low velocity. Due to the flexible chain of the thermoplastic polymers, a different 
behaviour under impact loading is expected respect to the thermosetting materials. Neither spalling nor debris is supposed to form, but a failure behaviour very close to conventional material made of metal and characterized by ductility is very probable to notice. In particular, impact tests with a drop dart device at various velocities fixing the mass were carried out on laminates with thicknesses from 3 to $7 \mathrm{~mm}$. The capability of energy absorption and the influence of the impact conditions were investigated. Such investigation is different from that carried out in previous works on PURE material ${ }^{53,56}$ for both experimental conditions and results. Previously, thinner specimens were tested varying the mass and analysing the impact penetration damage at different compaction temperatures and pressures. In this paper, the results of the impact tests are discussed in order to determine the impact behaviour of the thermoplastic composite and to study the sensitivity of the material to some impact parameters, taking constant temperature and pressure. The fully thermoplastic composite showed a different behaviour in terms of energy absorption and damage mechanisms if compared to the composites presented in literature. The experimental results also revealed sensitivity of the studied composites to level of impact energy. Some parameters of the test were influenced by the increase of the impact energy. These behaviours, together with the low density and the fully recyclability of this material, make it a very interesting solution for structural applications.

\section{Geometrical and material description of the investigated panel}

The material used in this work is a sealable, co-extruded three layer PP tape, with an A:B:A (copolymer: homopolymer:copolymer) structure, manufactured by DIT bv. This tape was subsequently woven into a balanced, plain weave fabric (long fibres with a tape orientation $\left.\left[0^{\circ}, 90^{\circ}\right]\right)$. Layers of this fabric are cut into square pieces and stacked in a close fitting mould up to a maximum depth of $7 \mathrm{~mm}$. It is necessary to pay attention to the processing conditions in order to obtain an interesting fully thermoplastic composite from the mechanical point of view. Pressure must be sufficient to prevent shrinkage by lateral constraining and guarantee good interfacial contact for bonding but not enough to produce flow of homopolymer core, implying a loss of properties. At the same time, temperature must be such to melt copolymer layer enabling fibre bonding, but not so much as to produce shrinkage, relaxation or melting of the oriented homopolymer phase. Therefore, the mould was subjected to heat $\left(\sim 150^{\circ}\right)$ and pressure $(\sim 10$ bar $)$ to consolidate the fabric plies into a biaxially reinforced composite laminate. In Table 1, the main mechanical properties of the tape and sheet configuration (obtained using a single layer) are reported according to the PURE technical data sheet. Moreover, from the
Table I. Mechanical properties of the PURE tape and sheet according to the technical data sheet provided by the manufacturer.

\begin{tabular}{lll}
\hline & Value & Unit \\
\hline $\begin{array}{lll}\text { PURE tape } \\
\text { Width }\end{array}$ & 2.2 & $\mathrm{~mm}$ \\
Density & 732 & $\mathrm{~kg} / \mathrm{m}^{3}$ \\
Tensile modulus & $\mathrm{I} 4$ & $\mathrm{GPa}$ \\
Tensile strength & 500 & $\mathrm{MPa}$ \\
Tensile strain to failure & 6 & $\%$ \\
Flexural modulus & $4.5-5.5$ & $\mathrm{GPa}$ \\
Shrinkage at I30 ${ }^{\circ} \mathrm{C}$ & $<5.5$ & $\%$ \\
PURE sheet & & \\
Thickness & 0.3 & $\mathrm{~mm}$ \\
Bulk density & 780 & $\mathrm{~kg} / \mathrm{m}^{3}$ \\
Tensile modulus & 5.5 & $\mathrm{GPa}$ \\
Tensile strength & 200 & $\mathrm{MPa}$ \\
Tensile strain to failure & 9 & $\%$ \\
Flexural modulus & $4.5-5.5$ & $\mathrm{GPa}$ \\
Sealing range & $\mathrm{I} 30-180$ & ${ }^{\circ} \mathrm{C}$ \\
\hline
\end{tabular}

literature ${ }^{53,57}$ is possible to recover other mechanical properties of the PURE material obtained with specific tests.

From Table 1, it can be noted how the tape density is less than the density of the isotropic PP $\left(\sim 910 \mathrm{~kg} / \mathrm{m}^{3}\right)$; this is due to the presence of microvoids during the drawing of homopolymer and copolymer molecules. Instead, the woven specimens, compacted at $1 \mathrm{MPa}$, have a density that exceeds the original tape without reach the isotropic PP value. The copolymer skin layer is, in fact, highly viscous even above the melting temperature and so higher pressure is necessary to flow into the voids caused by the surface roughness for the weave of the fabric.

In this work, three kinds of laminates were considered. They differed only for the shell thickness. The thicknesses of the considered laminates were 3, 5 and $7 \mathrm{~mm}$. They were obtained by the overlap of 23, 38 and 53 layers, respectively. As regards to the lamination, no angle variation was adopted, so each layer has the same fibres orientation. The specimens used in the work had a square geometry with the dimension of the edge equal to $100 \mathrm{~mm}$. A specimen with the thickness of $7 \mathrm{~mm}$ is shown in Figure 1.

\section{Low velocity normal impact tests}

A series of impact tests with a drop weight equipment were performed on the described specimens. The impact tests were carried out according to the ASTM D5628-96. ${ }^{58}$ In the tests carried out in this work, a mass of $67.3 \mathrm{~kg}$ is raised to a defined height and then released. The fall height depends on the requested value of impact energy. The mass was driven in its free fall with a couple of rails. A dart with a 


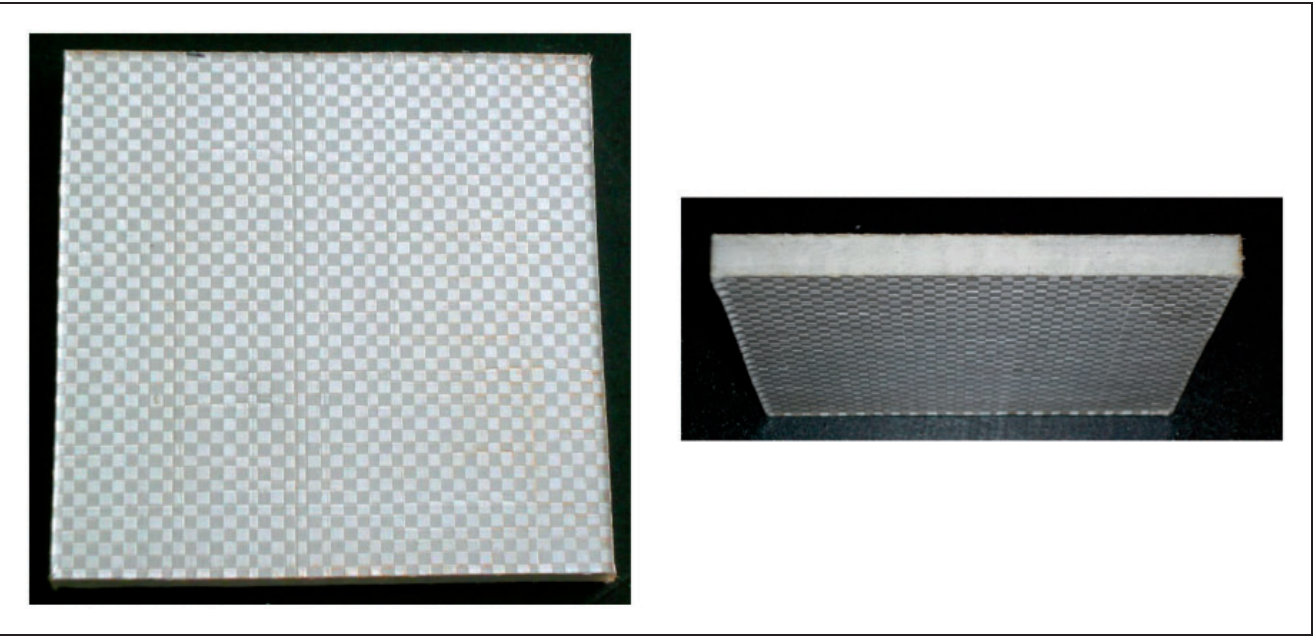

Figure I. Top and side view of a specimen with the thickness of $7 \mathrm{~mm}$.

hemispherical tip was fixed to the impact mass. The dart stroke the specimen at the end of its free fall. The diameters of the dart and of its tip were of $20 \mathrm{~mm}$. The testing device used for these tests was the Ceast 9350. The main parameters of the tests were the fall mass, which is applied to the dart and the fall height. Consequently, the other fundamental parameters of the tests were the impact velocity $v_{0}$ and the impact energy. The impact velocity $v_{0}$ was measured with a photocell just before the impact with the specimen. The testing machine has a maximum fall stroke of $1 \mathrm{~m}$ and it is equipped with a system of springs if higher impact energy is requested. A total equivalent fall height of $29 \mathrm{~m}$ could be reached. The load applied by the impactor was measured with a piezoelectric load cell when the dart was in contact with the specimen. The load cell was fixed behind the hemispherical tip and between the tip and the dart. The data acquisition system had a sampling frequency of $1 \mathrm{MHz}$ and no filters were applied on the force signal. During the tests, the flat specimens were clamped on their edges into the testing machine. The clamping device had a central circular hole with an internal diameter of $76 \mathrm{~mm}$, as shown in Figure 2.

The dynamic behaviour of the fully thermoplastic composite was studied evaluating the effect of the impact velocity $v_{0}$, and consequently of the impact energy, on the laminates with different thicknesses. To this aim, the experimental tests were carried out considering three different levels of the impact energy for each of the considered thickness, as shown in Table 2. The different levels of the impact energy were defined starting from the experience made by the authors in a previous study. ${ }^{59}$ The impact energies were defined considering the strength of the specimens and the capability of the testing machine. For these reasons, only for the thinnest specimens $(3 \mathrm{~mm})$, only two impact energies were considered. These specimens had a reduced strength compared to the specimens with a thickness of $7 \mathrm{~mm}$ and the value of the

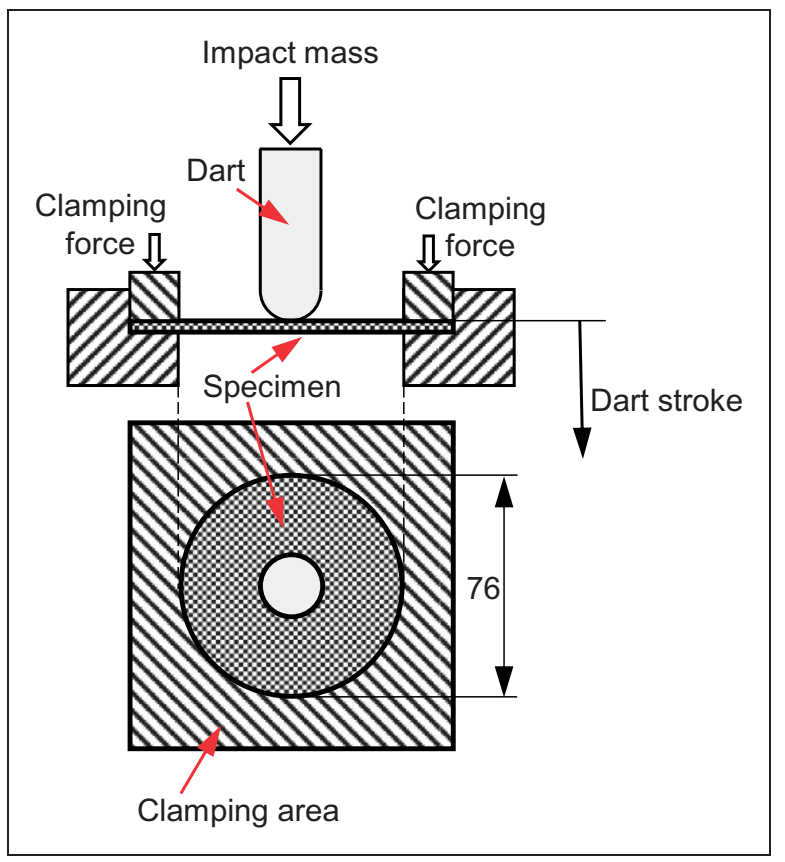

Figure 2. Experimental test configuration.

impact velocity equal to 0.74 was the minimum achievable value with the adopted testing equipment when an impact mass of $67.3 \mathrm{~kg}$ is used.

The input parameter used for the testing device was the impact velocity $v_{0}$. The values of the impact velocity were defined in order to obtain, as precisely as possible, the desired level of the impact energy. Three different repetitions were performed for each test configuration. The impactor was automatically stopped during the test, after rebounding, to avoid a second strike on the specimen. The results of the impact tests were analysed in terms of the force exchanged in the contact between the dart and the specimen and in terms of the energy absorbed by the specimen. Both these parameters were evaluated as a function of the stroke of the dart. The stroke of the dart was defined as shown in Figure 2. Moreover, the visual inspections 
Table 2. The values of the experimental parameters evaluated for all the considered configurations.

\begin{tabular}{|c|c|c|c|c|c|c|c|c|c|}
\hline Specimen label & $\begin{array}{l}\text { Energy } \\
\text { level }\end{array}$ & $\begin{array}{l}\text { Thickness } \\
(\mathrm{mm})\end{array}$ & $\begin{array}{l}\text { Impact } \\
\text { velocity } \\
(\mathrm{m} / \mathrm{s})\end{array}$ & $\begin{array}{l}\text { Impact } \\
\text { energy }(\mathrm{J})\end{array}$ & $\begin{array}{l}\text { Max. } \\
\text { contact } \\
\text { force }(k N)\end{array}$ & $\begin{array}{l}\text { Max. } \\
\text { deflection } \\
(\mathrm{mm})\end{array}$ & $\begin{array}{l}\text { Stiffness } \\
(\mathrm{N} / \mathrm{mm})\end{array}$ & $\begin{array}{l}\text { Absorbed } \\
\text { energy }(J)\end{array}$ & Perforation \\
\hline PURE_DP_TH3_04 & Level I & 3 & 0.744 & 28.499 & 4.427 & 14.926 & 211.407 & 28.020 & No \\
\hline PURE_DP_TH3_05 & & 3 & 0.746 & 32.551 & 3.873 & 20.974 & 235.175 & 30.995 & No \\
\hline PURE_DP_TH3_06 & & 3 & 0.746 & 31.042 & 4.198 & 18.642 & 234.498 & 29.434 & No \\
\hline PURE_DP_TH5_07 & & 5 & 0.745 & 24.410 & 5.463 & 8.671 & 421.760 & 24.410 & No \\
\hline PURE_DP_TH5_08 & & 5 & 0.745 & 24.164 & 5.680 & 8.260 & 388.705 & 24.164 & No \\
\hline PURE_DP_TH5_09 & & 5 & 0.746 & 24.325 & 5.612 & 8.506 & 391.998 & 24.325 & No \\
\hline PURE_DP_TH3_0I & Level 2 & 3 & 1.272 & 119.312 & 4.228 & 98.255 & 361.350 & 57.843 & Yes \\
\hline PURE_DP_TH3_02 & & 3 & $\mathrm{I} .344$ & 124.013 & 5.225 & 95.804 & 325.955 & 72.532 & Yes \\
\hline PURE_DP_TH3_03 & & 3 & 1.328 & 108.739 & 4.831 & 74.752 & 335.047 & 90.453 & Yes \\
\hline PURE_DP_TH5_0I & & 5 & 1.280 & 63.429 & 10.261 & 12.517 & 903.831 & 63.428 & No \\
\hline PURE_DP_TH5_02 & & 5 & 1.283 & 64.122 & 8.786 & 13.274 & 720.429 & 64.122 & No \\
\hline PURE_DP_TH5_03 & & 5 & 1.334 & 69.162 & 9.115 & 14.029 & 679.387 & 69.162 & No \\
\hline PURE_DP_02 & & 7 & 1.330 & 67.160 & 11.694 & 11.566 & 1014.023 & 67.159 & No \\
\hline PURE_DP_03 & & 7 & 1.330 & 67.259 & 11.628 & 11.717 & 984.131 & 67.259 & No \\
\hline PURE_DP_I4 & & 7 & 1.359 & 70.068 & 11.605 & 12.013 & 984.907 & 70.170 & No \\
\hline PURE_DP_TH5_04 & Level 3 & 5 & 2.064 & 209.609 & 9.202 & 100.357 & 834.947 & 189.584 & Yes \\
\hline PURE_DP_TH5_05 & & 5 & 2.092 & 229.406 & 10.052 & 124.367 & 879.292 & 180.213 & Yes \\
\hline PURE_DP_TH5_06 & & 5 & 2.084 & 223.674 & 9.728 & 117.498 & 862.914 & 191.999 & Yes \\
\hline PURE_DP_I5 & & 7 & 2.082 & 147.070 & 16.475 & 1.787 & 887.166 & 157.253 & No \\
\hline PURE_DP_I6 & & 7 & 2.089 & | 48.092 & 16.263 & 1.889 & 848.665 & 158.726 & No \\
\hline PURE_DP_I7 & & 7 & 2.087 & 158.470 & 15.954 & 18.125 & 857.917 & 158.953 & No \\
\hline PURE_DP_I8 & Level 4 & 7 & 3.218 & 367.210 & |9.79| & 28.371 & 730.826 & 367.628 & No \\
\hline PURE_DP_19 & & 7 & 3.215 & 366.648 & 20.445 & 28.387 & 872.831 & 367.638 & No \\
\hline PURE_DP_20 & & 7 & 3.215 & 367.115 & 19.317 & 29.276 & 826.475 & 366.062 & No \\
\hline
\end{tabular}

of the damaged specimens at the end of the test were provided.

\section{Experimental results}

The force at the contact between the impactor and the specimen as a function of the time history was recorded during the test. The stroke of the dart, from the instant of the impact with the specimen (Figure 2), was calculated dividing the force history by the mass of the impactor. The results were then integrated with respect of the time using the initial impact velocity $v_{0}$. The kinetic energy of the impactor at the instant of the contact with the specimen was defined as the impact energy $E$. This was the energy transferred to the composite specimen. A portion or the total amount of the impact energy was absorbed by the composite specimen in forms of material damage, heat generation and other mechanisms. ${ }^{60}$

In the drop dart tests, the damage mode and the corresponding behaviour of the composite can be deducted from the shape of the diagram forcedisplacement. Figure 3 shows two typical charts where the force in the contact between the dart and the specimen is plotted as a function of the deflection of the specimen for non-perforated (2a) and

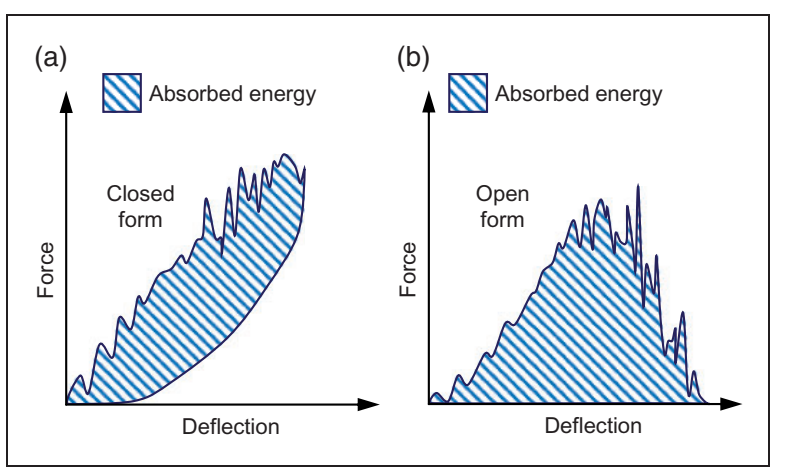

Figure 3. Typical force-deflection curve for (a) a non-perforated sample (closed form) and (b) perforated sample (open form).

perforated ( $2 b)$ samples. The deflection of the specimen is evaluated as the stroke of the dart from the contact instant with the specimen (Figure 2). A closed curve means no perforation of the laminate (Figure 3(a)), whereas, if an open curve is observed, perforation is present in the specimen (Figure 3(b)). ${ }^{61}$ The same trend can be observed for both charts during the loading phase of impact. The shaded areas visible in Figure 3(a) and (b) represent the 
amount of the absorbed energy in non-perforated and perforated samples, respectively.

The load vs. displacement curves for all the tested configurations are summarized in Figure 4. The figure shows as during the impact loading hysteresis cycles were obtained. This trend represented how the impact energy is absorbed by the specimen. The absorbed energy was evaluated as the area enclosed by the force vs. displacement curves. The force-displacement curves can be observed with more detail in Figure 5, where only one repetition for each configuration is represented, in order to better examine the results of the considered levels of energy for each thickness. The chart in Figure 5 clearly put in evidence as the specimens showed different types of impact damage, as for a generic structure made of FRP composite. ${ }^{62,63}$ In more details, the specimens with the thickness of 3 and $5 \mathrm{~mm}$ impacted with the energy level 2 and 3, respectively, showed perforation. Indeed, in the unloading phase the force changes abruptly causing unstable behaviour of the perforated laminate. In all the other test configurations, the dart had a behaviour of rebounding or penetration. The chart for specimen with a thickness of $5 \mathrm{~mm}$, subjected to the level 2 of energy did not have a completely open form. This means that the laminated plate was at the perforation threshold. Indeed, the deflection of the specimens grew and then it decreased in the first

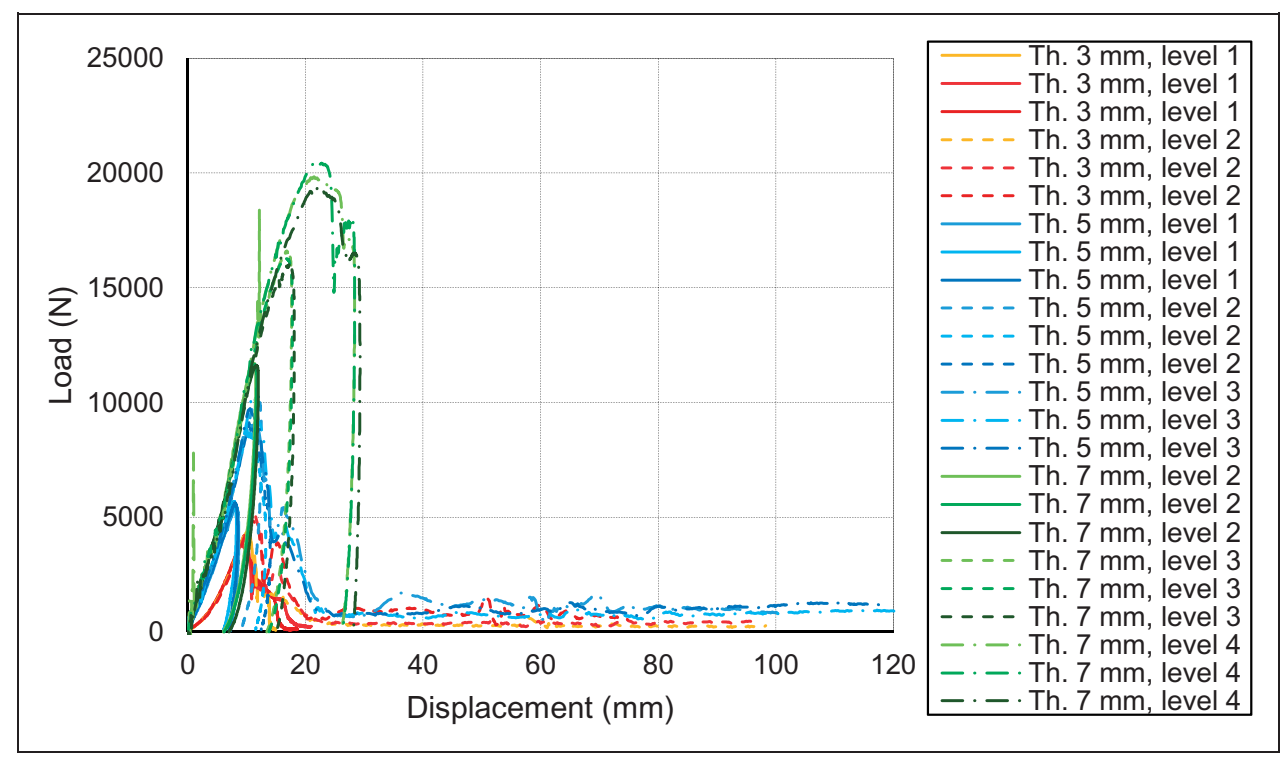

Figure 4. Load vs displacement curves for the tested laminates.

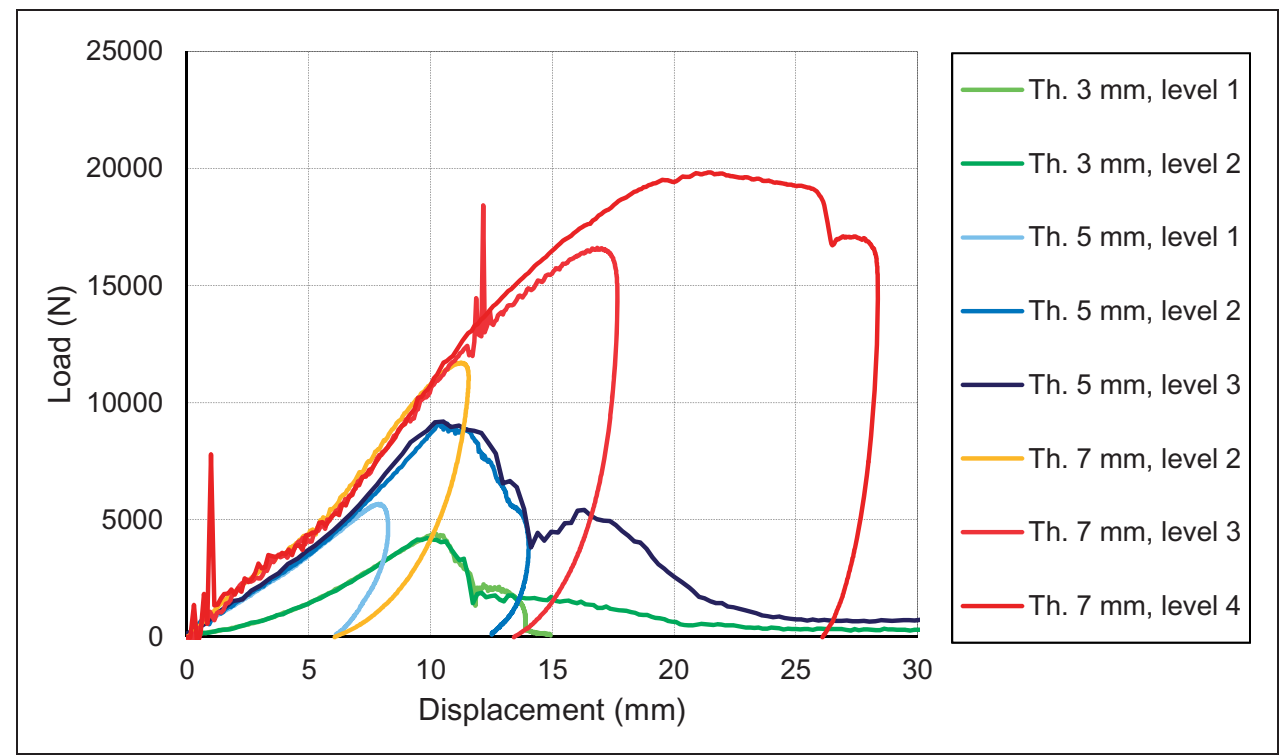

Figure 5. Detailed load vs displacement curves (only a single curve for each test configuration is shown). 


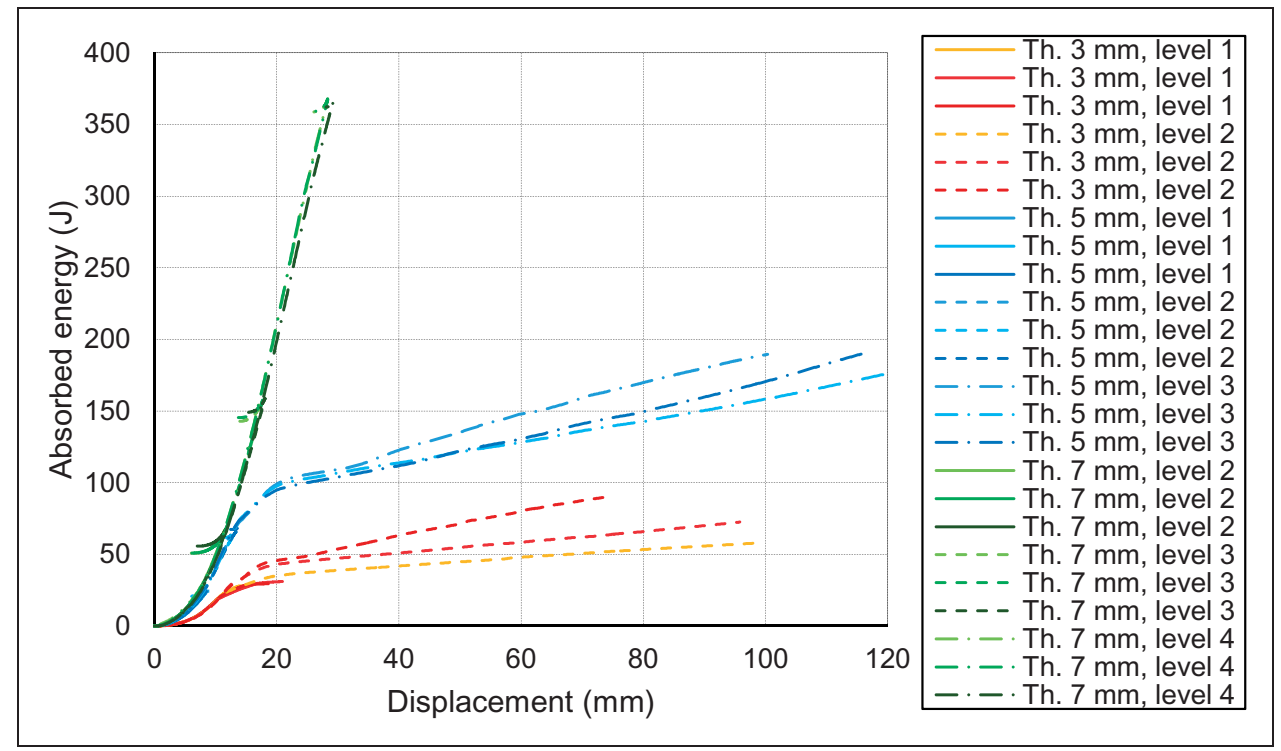

Figure 6. The energy-displacement histories for the tested laminates.

instants of the unloading phase. Moreover, it is evident how, increasing the impact energy, the plastic damage was much more pronounced. For the laminate with a thickness of $7 \mathrm{~mm}$, for example, the permanent deflection after the impact was about $54 \%$, $82 \%$ and $93 \%$ respect to the maximum one, increasing the energy level. The permanent deflection could be obtained as the ratio between the last deformation of the unloading phase and the maximum deflection.

The results of the impact tests are showed in terms of energy vs. displacement of the dart curves in Figure 6 for all the considered configurations. The effect of the impact energy with a constant mass of impact was investigated analysing the experimental results. From Figures 4 to 6 clearly emerges as the maximum contact force between the specimen and the dart, the maximum stroke of the dart and the energy absorbed by the specimen grew up with the increase of the impact energy. The curves obtained with the different levels of energy at the same thickness condition tended to follow the same trend of the specimens subjected to perforation in the first part of the diagram. Such aspect seemed to be different from the FRP laminates. In case of perforation at the higher energy levels, the force peak tended to reduce respect to that obtained in the impacted plate by a lower level of energy where non-perforation was observed. ${ }^{61}$ This was due because the perforation can cause a drastic decline in the bending stiffness of the specimen. However, the curves obtained with the lower energy had a smaller shape. Higher was the energy level, higher was the displacement of the dart. Consequently, the area enclosed by the curve was higher.

The behaviour of the specimen during the impact can be divided in three phases. These phases are related to quasi-elastic, plastic and damping absorption of energy. The damping energy was absorbed during rebound of the impactor, hence in the phase when the stroke of the dart decreased. Figure 5 clearly emerged as the curves of the specimens subjected to perforation had a different trend. The load, after reaching its maximum value, had a deep drop increasing the dart displacement. Going into further details, different damage modes were observed. In some cases, the specimens showed a damage due to the impact clearly visible with the naked eye. In some other cases, the damage was characterized by internal defects. In these cases, the damage consisted of matrix cracking and fibre breakage, which usually cannot be detected by a simple exam of the surface of the specimen ${ }^{64}$ Analysing the effects of the laminate thickness on the impact behaviour, the impact damages have been more extensive in the thin laminates than in the thick ones as expected also for the FRP composites. ${ }^{65}$ The damage in the thin laminates was distributed through the whole thickness, whereas the damage in the thick plate could be detected only in the upper layers of the laminate. The initiation and growth of delamination were much more evident for the thicker specimens, whereas for the thinner ones the matrix crack, the fibre fracture and the fibre pull-out were the main damage mechanisms. From literature, it was also observed that the delamination increases with the plate thickness. ${ }^{66}$ The fully PP composite studied in this work showed a ductile behaviour and a developed extended plasticity without a crack tip making them less sensitive to damage from lower energy impacts, unlike the common FRP composites where the brittle nature can drastically reduce the residual mechanical properties of the composite. Photographs of the damaged laminates with a thickness of 7,5 and $3 \mathrm{~mm}$ are reported in Figure 7, for a clearer view of the impact process. The impacted surface (front of the specimen) and the non-impacted surface (back of the specimen) showed the damage propagation for the level 2 of energy. For the thicker 

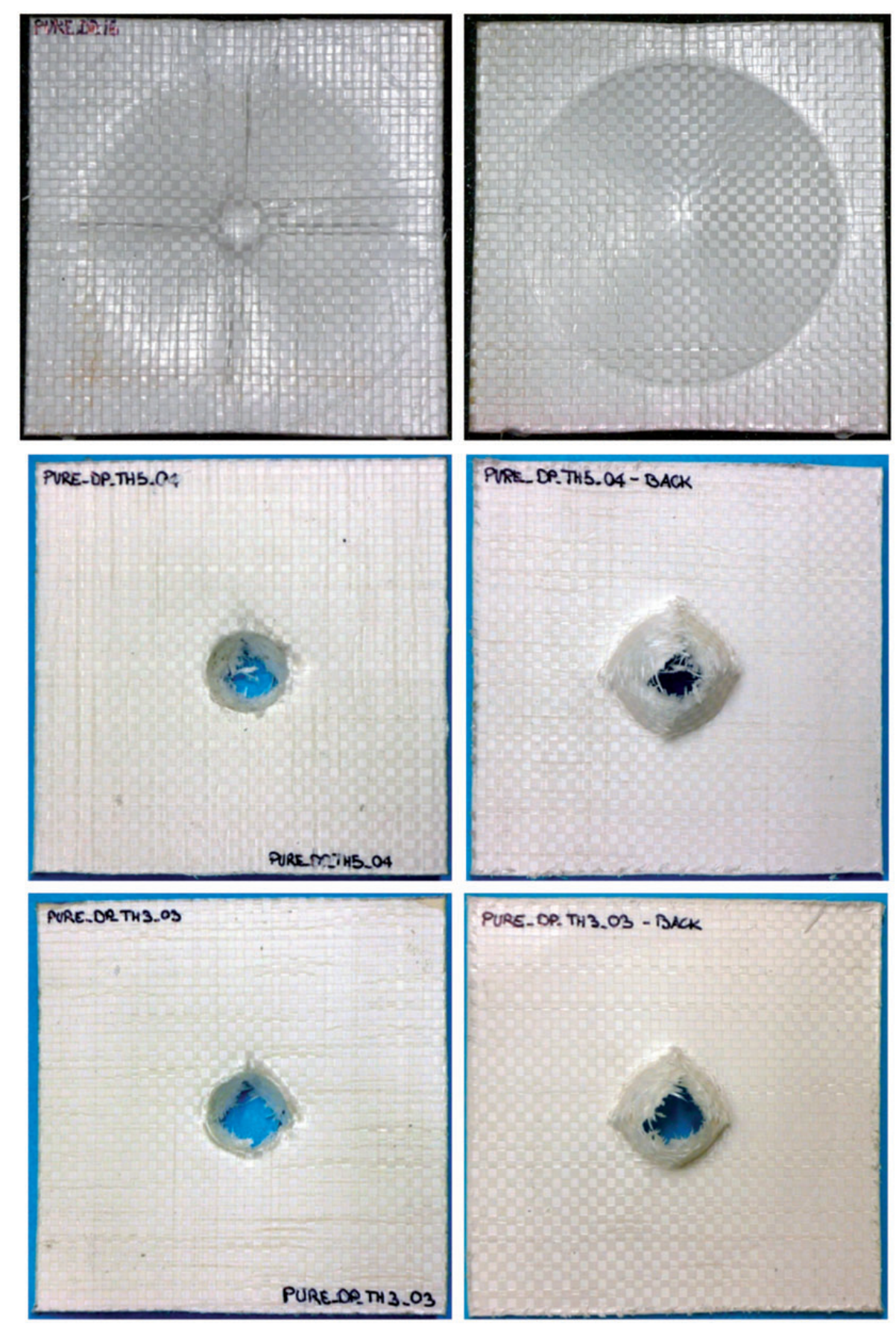

Figure 7. Plate specimens after the impact tests with energy level 2. On the top, the specimen with a thickness of $7 \mathrm{~mm}$, in the middle, the specimen with a thickness of $5 \mathrm{~mm}$, on the bottom, the specimen with a thickness of $3 \mathrm{~mm}$. On the left hand view of the surface of the specimen in contact with the dart, on the right hand back view of the specimen.

specimen, a cross yarn sliding along the $0^{\circ}$ and $90^{\circ}$ direction on the top surface and an extended plastic cap formation in the rear skin were evident. Such deformation cannot be present into thermoset composites, which exhibit brittle fracture with low elastic limits even when subjected to no penetrative impact loads. The behaviour of composite changed when the thickness decreased up to $3 \mathrm{~mm}$. Consequently, the impact response was altered. The deformation on the top surface was much more concentrated around the impact point for the specimens with a thickness of 5 and $3 \mathrm{~mm}$. The damage propagation was along the warp and weft directions, as evident on the back face, contrarily to what happens for FRP laminates where the damage propagates along the weaker $45^{\circ}$ direction. $^{61}$

The experimental results were further elaborated evaluating a series of parameters in order to study the impact behaviour of the laminates. In particular, the peak values of the contact force, the maximum 


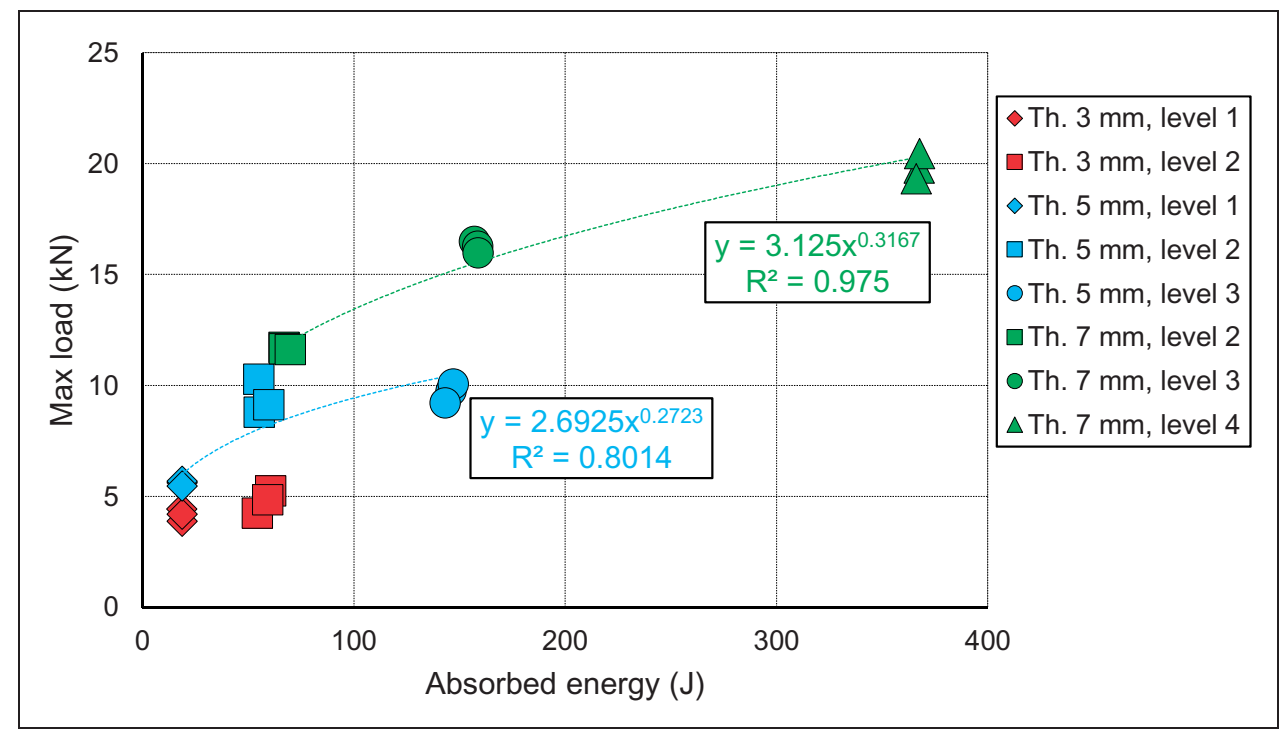

Figure 8. The trend of the maximum load as a function of the absorbed energy.

deflection of the specimen, the stiffness of the specimen and the energy absorbed by the specimen were calculated. The values of these parameters are summarized in Table 2. The stiffness was evaluated as the slope of the first linear part of the load-displacement curve. The maximum deflection of the specimen corresponds to the maximum stroke of the dart (Figure 2). In Table 2, it is possible to observe as the value of the absorbed energy is higher than the value of the impact energy for some of the specimens with a thickness of $7 \mathrm{~mm}$. However, as discussed by the authors in Boria et al. ${ }^{59}$ some of the experimental tests with these specimens were affected by a slip phenomenon between the specimen and the clamping device during the impact. The absorbed energy is evaluated integrating the curve of the force applied by the dart vs the displacement of the dart. The displacement of the dart is evaluated integrating two times the acceleration of the dart, which is obtained dividing the signal of the force by the impact mass. Therefore, the slip effect caused an overestimation of the displacement of the dart. Consequently, the absorbed energy was overestimated and it seemed to be higher than the impact energy.

The maximum load as a function of the absorbed energy is shown for all the considered configurations in Figure 8. The maximum load tended to increase almost linearly with the growth of the absorbed energy in all the considered cases. The growth of the load tended to an asymptotic value approaching to the perforation condition. Indeed, the data were better fitted with a polynomial relation than with a linear one. In particular, an increment of the impact energy (from a level to the following one) tended to almost doubling the maximum load. This aspect was not evident for the specimens with a thickness of $3 \mathrm{~mm}$ where the level 1 of energy was very close to the perforation condition. As expected, the same trend can be also observed in Figure 9, where the maximum load is reported as a function of the impact velocity. Concluding, the thickness of the laminate and the impact velocity influenced the impact behaviour of the PURE thermoplastic with an increase in term of the maximum load up to a threshold value, where perforation condition was reached.

The influence of the impact velocity on the absorbed energy is shown in Figure 10. The elaboration of the results put in evidence a square dependency between the absorbed energy and the velocity as expected. The experimental data of the stiffness as a function of the impact velocity were arranged in a discordant way. A linear growth was evident for the thinner specimens, whereas an opposite trend was noticed for the specimens with the highest thickness, as shown in Figure 11. Moreover, it was clear that the bending stiffness increased as the thickness and number of layers increased, as for the FRP laminates. ${ }^{61}$ The growth of the stiffness varying the thickness was much more pronounced for the lower energy levels. The value of the stiffness tended to stabilize around the value of $800 \mathrm{~N} / \mathrm{mm}$ for the maximum value of the impact energy. Unlike the thermosetting composites, the slope of the interpolating line of the maximum values of the force-displacement curves was not a material constant: it seemed to depend on the impact energy. Figure 12 shows the maximum values of the force as a function of the bending stiffness for all the impact energies. The data were well fitted with a linear relationship of growth as for the FRP composites, ${ }^{61}$ for the specimens with a thickness of 3 and $5 \mathrm{~mm}$. Opposite behaviour was observed for the specimen with the thickness of $7 \mathrm{~mm}$. The data were again fitted with a linear relation but the slope was negative. This was probably due to sliding problems on the grab device. 


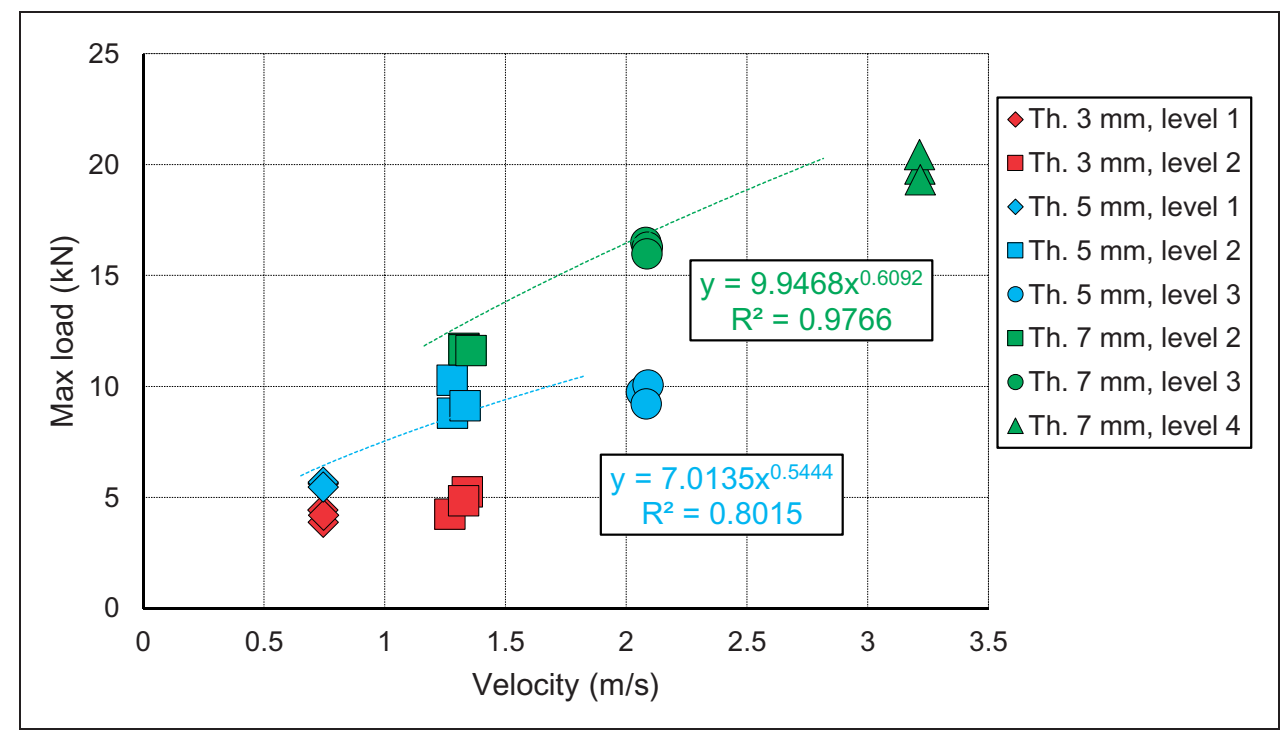

Figure 9. The trend of the maximum load as a function of the impact velocity.

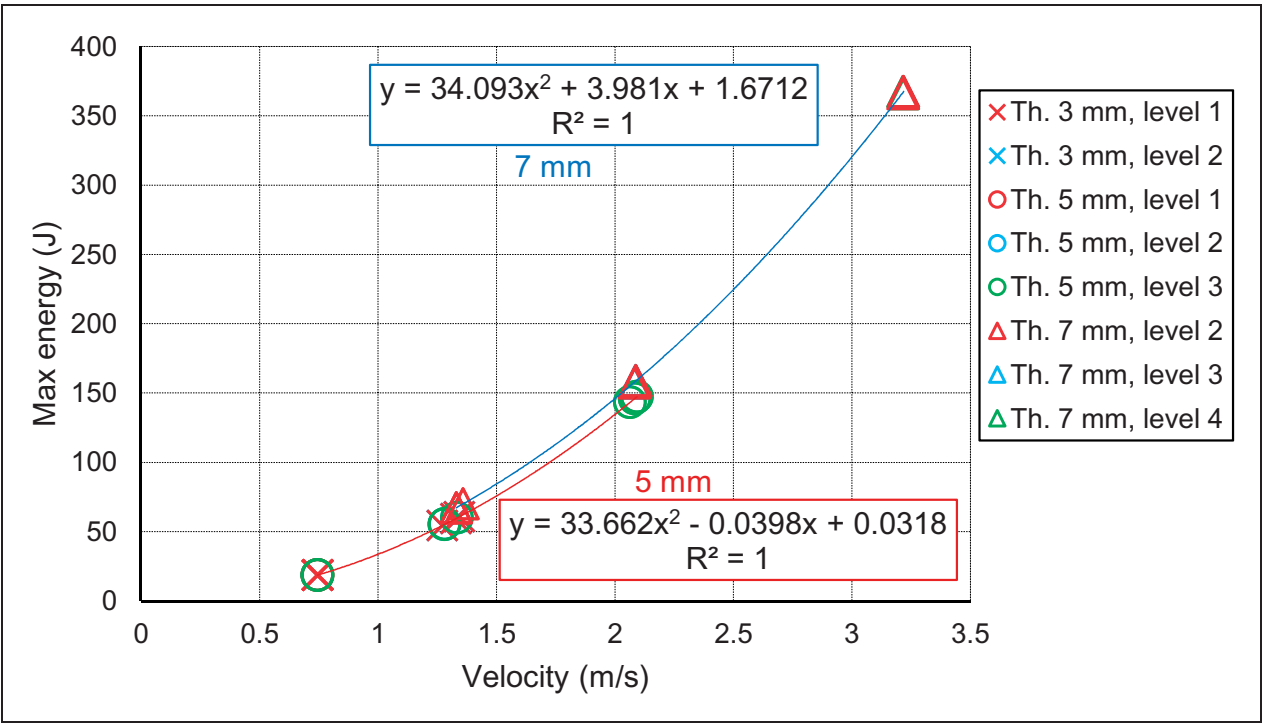

Figure 10. The trend of the absorbed energy as a function of the impact velocity.

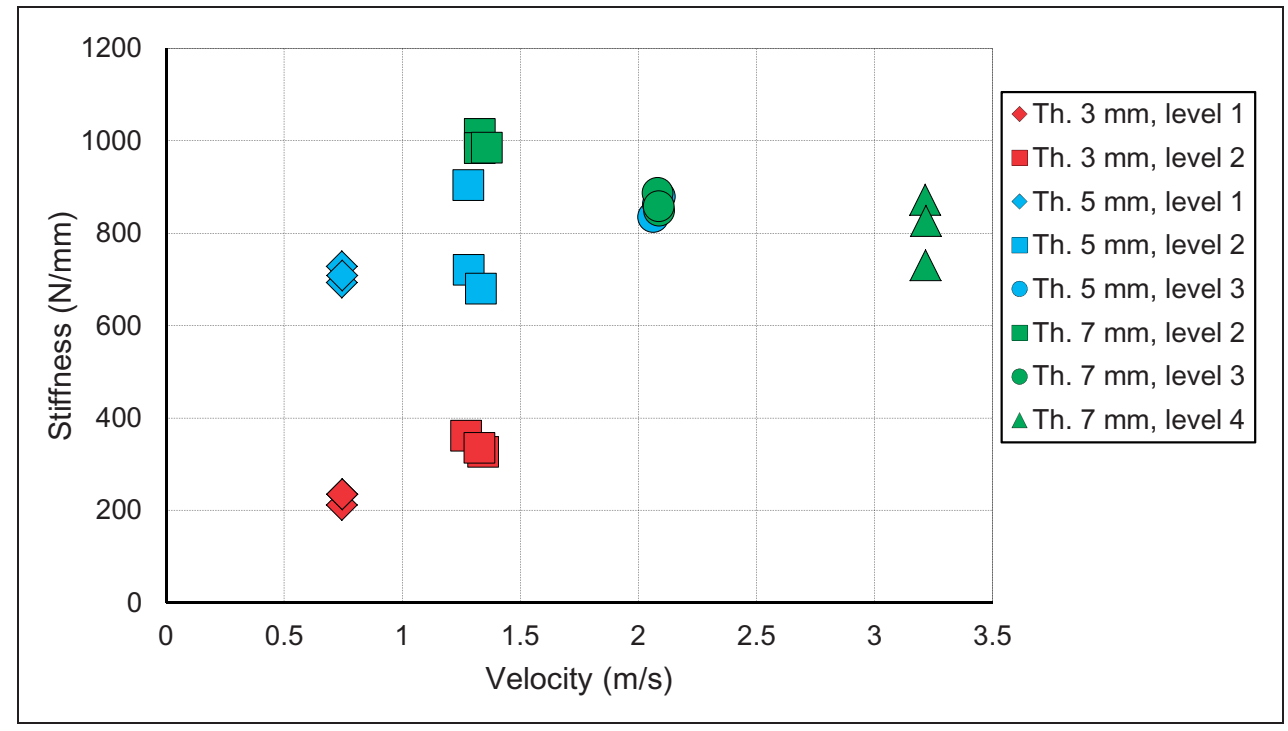

Figure II. The trend of the stiffness as a function of the impact velocity. 


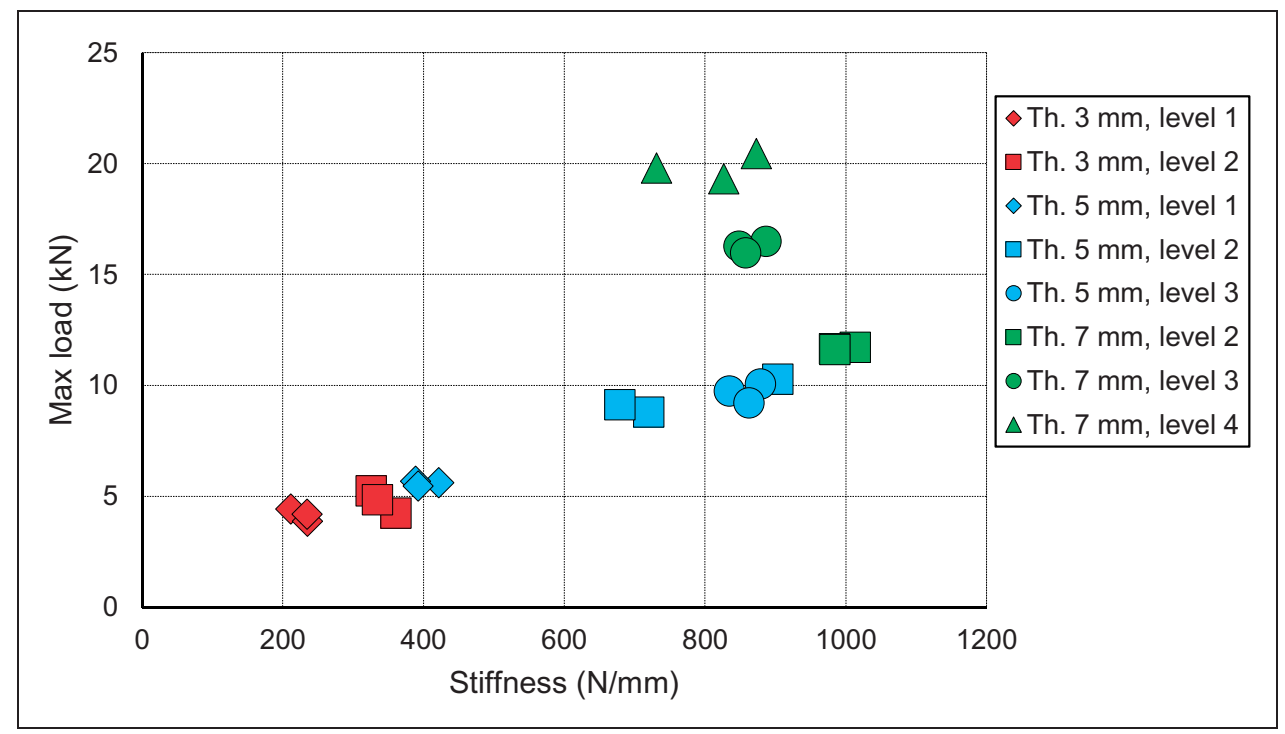

Figure 12. The trend of the maximum contact force as a function of bending stiffness.

The experimental results revealed that the response of the thermoplastic laminates to lowvelocity impact was very sensitive to the thickness and to the level of the impact energy, as observed for the FRP laminates. ${ }^{61,67}$

\section{Conclusions}

This work highlighted the main impact properties of a new type of material. In particular, the paper deals with the experimental investigation of the behaviour of a fully thermoplastic composite when subjected to LVIs. The material analysed was a composite laminate obtained overlaying $0-90^{\circ}$ plain weaves. It was made of a matrix and a reinforcement both of PP material and obtained with the patented PURE technology. For this reason, the material is commercially known as PURE thermoplastic. A series of drop dart impact tests were carried out on laminates made of this material. Specimens with three different thicknesses were investigated. Moreover, four different energies of impact were considered, to study the capability of energy absorption of the material. The literature review carried out put in evidence a lack of results about composites with both the matrix and the reinforcement made of thermoplastic, when subjected to impact loading. In this work, the PURE thermoplastic showed a different behaviour, in conditions of impact at low velocity, compared to the materials presented in the literature. The experimental results highlighted the influence of the thickness of the laminate on the impact behaviour. With the considered low thickness, a perforation of the specimens was observed, whereas a ductile behaviour and extended plasticity without a crack tip was obtained with the considered high thickness. The influence of the thickness on the deformation behaviour was also confirmed examining the stiffness of the specimens during the impact. The value of the stiffness of the specimens showed a reduction during the impact process. This trend was due to a compaction mechanism of the different layers of the material. At the same time, the compaction mechanism avoided the fracture of the specimen, which showed a ductile behaviour. This behaviour was very different compared to that obtained with the thermoset composites, widely demonstrated in the literature, which are usually characterized by a brittle behaviour during the impact process. Further difference, in comparison to the composites studied in the literature, was found examining the maximum value of the contact force between the dart and the specimen. With the PURE thermoplastic, with the high levels of the considered energy of impact, the value of the force was lower than at the low levels of the considered energy of impact. The specimens were perforated by the dart in the first case but not in the second one. Consequently, the PURE thermoplastic showed high sensitivity to the impact energy level, considering the conditions studied in this work. The impact damage was more extensive in the thin laminates than in the thick ones. The damage in the thin laminates was distributed through the whole thickness, whereas the damage in the thick plate was detected only in the upper layers of the laminate. The initiation and the growth of the delamination was much more evident for the specimens with the high thickness, whereas for the specimen with the low thickness, the matrix crack, the fibre fracture and the fibre pull-out were the main damage mechanisms.

\section{Declaration of Conflicting Interests}

The author(s) declared no potential conflicts of interest with respect to the research, authorship, and/or publication of this article.

\section{Funding}

The author(s) received no financial support for the research, authorship, and/or publication of this article. 


\section{ORCID iD}

Simonetta Boria (D) http://orcid.org/0000-0003-2073-4012

\section{References}

1. Belingardi G and Chiandussi G. Vehicle crashworthiness design-general principles and potentialities of composite material structures. In: Abrate $\mathrm{S}$ (ed) Impact engineering of composite structures. Wien: Springer, 2011, pp.193-264.

2. Belingardi $G$ and Scattina A. Experimental investigation on the bending behaviour of hybrid and steel thin walled box beams-The role of adhesive joints. Int $J$ Adhes Adhes 2013; 40: 31-37.

3. Airale A, Carello M and Scattina A. Carbon fiber monocoque for a hydrogen prototype for low consumption challenge. Materialwissenschaft und werkstofftechnik 2011; 42: 386-392.

4. Regulation (EC) No 715/2007 (20.6.2007) and $\operatorname{COM}(2017) 676$ final/2 (26.1.2018) of the European Parliament and of the Council (http://eur-lex.europa.eu/).

5. Helms $\mathrm{H}$ and Lambrecht $\mathrm{U}$. The potential contribution of light-weighting to reduce transport energy consumption. Int J Life Cycle Assess 2007; 12: 58-64.

6. Duflou JR, De Moor J, Verpoest I, et al. Environmental impact analysis of composite use in car manufacturing. CIRP Ann-Manuf Technol 2009; 58: 9-12.

7. Bonnett RE, Kulkarni H, Lim G, et al. Design and fabrication of automotive components in graphite fiber-reinforced composites. SAE Technical Paper, $790031,1979$.

8. Brylawski MM and Lovins AB. Ultralight-hybrid vehicle design: overcoming the barriers to using advanced composites in the automotive industry. Proc Int SAMPLE Symp Exhib 1996; 41: 1432-1446.

9. Jacob GC, Fellers JF, Simunovic S, et al. Energy absorption in polymer composites for automotive crashworthiness. J Compos Mater 2002; 36: 813-849.

10. Abrate $\mathrm{S}$. Modeling of impacts on composite structures. Compos Struct 2001; 51: 129-138.

11. Belingardi G, Boria S and Obradovic J. Energy absorbing sacrificial structures made of composite materials for vehicle crash design. In: Abrate S, et al. (eds) Dynamic failure of composite and sandwich structures, solid mechanics and its applications, vol. 192. The Netherlands: Springer, 2013, pp.577-609.

12. Mantena R, Mann R and Nori C. Low-velocity impact response and dynamic characteristics of glass-resin composites. J Reinf Plast Compos 2001; 20: 513-533.

13. Sjoblom PO, Hartness JT and Cordell TM. On low-velocity impact testing of composite materials. J Compos Mater 1988; 22: 30-52.

14. Cantwell WJ and Morton J. The impact resistance of composite materials-a review. Composites 1991; 22: 347-362.

15. Abrate S. Impact on composite structures. New York: Cambridge University Press, 2005.

16. Richardson MOW and Wisheart MJ. Review of lowvelocity impact properties of composite materials. Compos A 1996; 27: 1123-1131.

17. Anderson $\mathrm{T}$ and Madenci E. Experimental investigation of low-velocity impact characteristics of sandwich composites. Compos Struct 2000; 50: 239-247.
18. Tita V, Carvalho J and Vandepitte D. Failure analysis of low velocity impact on thin composite laminates: Experimental and numerical approaches. Compos Struct 2008; 83: 413-428.

19. Wang J, Waas AM and Wang H. Experimental and numerical study on the low velocity impact behavior of foam-core sandwich panels. Compos Struct 2013; 96: $298-311$.

20. Boria S, Scattina A and Belingardi G. Axial energy absorption of CFRP truncated cones. Compos Struct 2015; 130: 18-28.

21. Feraboli P and Kedward KT. A new composite structure impact performance assessment program. Compos Sci Technol 2006; 66: 1336-1347.

22. Lopes CS, Seresta O, Coquet Y, et al. Low-velocity impact damage on dispersed stacking sequence laminates. Part I. Experiments. Compos Sci Technol 2009; 69: 926-936.

23. Tita V, Carvalho J and Vandepitte D. Failure analysis of low velocity impact on thin composite laminates: experimental and numerical approaches. Compos Struct 2008; 83: 413-428.

24. Aktas M, Atas C, Icten BM, et al. An experimental investigation of the impact response of composite laminates. Compos Struct 2009; 87: 307-313.

25. Bussadori MBP, Schuffenhauer $\mathrm{K}$ and Scattina A. Modelling of CFRP crushing structures in explicit crash analysis. Compos Part B: Eng 2014; 60: 725-735.

26. Choi IH. Low-velocity impact analysis of composite laminates under initial in plane load. Compos Struct 2008; 86: 251-257.

27. Olsson R. Analytical prediction of large mass impact damage in composite laminates. Compos Part A 2001; 32: 1207-1215.

28. Donadon MV, Iannucci L, Falzon BG, et al. A progressive failure model for composite laminates subjected to low velocity impact damage. Comput Struct 2008; 86: 1232-1252.

29. Barbero EJ. Finite element analysis of composite materials. Boca Raton, FL: CRC Press, 2007.

30. Riccio A, Saputo S, Raimondo A, et al. Modeling low velocity impact phenomena on composite structures. In: Lopresto V, et al. (eds) Dynamic response and failure of composite materials and structures. Duxford: Woodhead Publishing, 2017, pp.129-158.

31. Shi Y, Swait T and Soutis C. Modeling damage evolution in composite laminates subjected to low velocity impact. Compos Struct 2012; 94: 2902-2913.

32. Raimondo L, Iannucci L, Robinson $\mathrm{P}$, et al. A progressive failure model for mesh-size-independent FE analysis of composite laminates subject to lowvelocity impact damage. Compos Sci Technol 2012; 72: 624-632.

33. Kim EH, Rim MS, Lee I, et al. Composite damage model based on continuum damage mechanics and low velocity impact analysis of composite plates. Compos Struct 2013; 95: 123-134.

34. de Moura MFSF and Marques AT. Prediction of low velocity impact damage in carbon-epoxy laminates. Compos Part A 2002; 33: 361-368.

35. Khalili SMR, Soroush M, Davar A, et al. Finite element modeling of low-velocity impact on laminated composite plates and cylindrical shells. Compos Struct 2011; 93: $1363-1375$. 
36. Xu S and Chen PH. Prediction of low velocity impact damage in carbon/epoxy laminates. Proc Eng 2013; 67: 489-496.

37. Directives 2000/53/EC on end-of-live vehicles (ELV) (18 September 2000) and 2005/64/EC on the type-approval of motor vehicles with regard to their reusability, recyclability and recoverability (26 November 2005) of the European Parliament and of the Council, http://eurlex.europa.eu/

38. Brown K, Brooks R and Warrior N. Characterizing the strain rate sensitivity of the tensile mechanical properties of a thermoplastic composite. J Miner Metal Mater Soc 2009; 61: 43-46.

39. Chang IY and Lees JK. Recent development in thermoplastic composites: a review of matrix systems and processing methods. J Thermoplast Compos 1988; 1: 277-296.

40. Lee RJ. Compression strength of aligned carbon fibrereinforced thermoplastic laminates. Composites 1987; 18: 35-39.

41. Vieille B, Casado VM and Bouvet C. About the impact behavior of woven-ply carbon fiber-reinforced thermoplastic- and thermosetting-composites: a comparative study. Compos Struct 2013; 101: 9-21.

42. Hufenbach W, Bohm R, Thieme M, et al. Polypropylene/glass fibre 3D-textile reinforced composites for automotive applications. Mater Des 2011; 32: 1468-1476.

43. Bernet N, Michaud V, Bourban PE, et al. Commingled yarn composites for rapid processing of complex shapes. Compos Part A: Appl S 2001; 32: $1613 \mathrm{e} 26$

44. Wakeman MD, Cain TA, Rudd CD, et al. Compression moulding of glass and polypropylene composites for optimised macro- and micromechanical properties-1 commingled glass and polypropylene. Compos Sci Technol 1998; 58: 1879-1898.

45. Trudel-Boucher D, Fisa B, Denault J, et al. Experimental investigation of stamp forming of unconsolidated commingled E-glass/polypropylene fabrics. Compos Sci Technol 2006; 66: 555-570.

46. Mazumdar S. Composites manufacturing: materials, product, and process engineering. Florida: CRC Press, 2001.

47. Selver E, Potluri $\mathrm{P}, \operatorname{Hogg} \mathrm{P}$, et al. Impact damage tolerance of thermoset composites reinforced with hybrid commingled yarns. Compos Part B 2016; 91: 522-538.

48. Capiati NJ and Porter RS. The concept of one polymer composites modelled with high density polyethylenes. J Mater Sci 1975; 10: 1671-1677.

49. Peijs T, Jacobs MJN and Lenstra PJ. High performance polyethylene fibers. In: Kelly A and Zweben C (eds) Comprehensive composite materials. Oxford: Pergamon Press, 2000.

50. Sakurada I, Ito T and Nakamae K. Elastic moduli of the crystal lattices of polymers. J Polym Sci: Part C 1966; 15: 75-91.
51. Matsuo M, Sawatari C and Nakano T. Ultradrawing of isotactic polypropylene films produced by gelation/ crystallization from solution. Polym $J$ 1986; 18: 759-774.

52. Hine PJ, Ward IM, Olle RH, et al. The hot compaction of high modulus melt-spun polyethylene fibres. $J$ Mater Sci 1993; 28: 316-324.

53. Alcock B. Single polymer composites based on polypropylene: Processing and properties. PhD Thesis, Queen Mary, University of London, UK, 2004.

54. Schimanski T. High-performance polypropylene structures for ecofriendly, fully recyclable composites. $\mathrm{PhD}$ Thesis, Technische Universiteit Eindhoven, Netherlands, 2002.

55. Cabrera N. O. Recyclable all-polypropylene composites: concept, properties and manufacturing. PhD Thesis, Technische Universiteit Eindhoven, Netherlands, 2004.

56. Alcock B, Cabrera NO, Barkoula N-M, et al. Low velocity impact performance of recyclable all-polypropylene composites. Compos Sci Technol 2006; 66: 1724-1737.

57. Boria S, Scattina A and Belingardi G. Experimental evaluation of a fully recyclable thermoplastic composite. Compos Struct 2016; 140: 21-35.

58. ASTM D5628-96. Standard test method for impact resistance of flat, rigid plastic specimens by means of a falling dart (tup or falling mass).

59. Boria S, Scattina A and Belingardi G. Impact behaviour of a fully thermoplastic composite. Compos Struct 2017; 167: 63-75.

60. Liu D, Raju BB and Dang X. Impact perforation resistance of laminated and assembled composite plates. Int $J$ Impact Eng 2000; 24: 733-746.

61. Hassan MA, Naderi S and Bushroa AR. Low-velocity impact damage of woven fabric composites: Finite element simulation and experimental verification. Mater Des 2014; 53: 706-718.

62. Aktas M, Atas C, Icten BM, et al. An experimental investigation of the impact response of composite laminates. Compos Struct 2009; 87: 307-313.

63. Erbil E. Impact loading in laminated composites. Izmir, Dokuz Eylül University: MSc Thesis, Mechanical Engineering, 2008.

64. Sultan MTH, Hodzic A, Staszewski WJ, et al. A SEMbased study of structural impact damage. Appl Mech Mater 2010; 24-25: 233-238.

65. Nilsson S, Bredberg A and Asp LE. Effects of CFRP laminate thickness on the bending after impact strength. Plast Rubber Compos 2009; 38: 61-66.

66. Amaro AM, Reis PNB, de Moura $M$, et al. Influence of the specimen thickness on low velocity impact behavior of composites. J Polym Eng 2012; 32: 53-58.

67. Belingardi $\mathrm{G}$ and Vadori R. Influence of the laminate thickness in low velocity impact behavior of composite material plate. Compos Struct 2003; 61: 27-38. 